\title{
Epidemiology pattern of traumatic injuries of adults older than 15 years in Kashan, Iran: A population-based study in 2018-2019
}

\author{
Zahra Sehat $^{1 *}$ (D), Esmaeil Fakharian ${ }^{1,2}$, Mojtaba Sehat $^{1}$, Abdollah Omidi $^{1,3}$
}

Received: 20 May 2020

Published: 15 May 2021

\section{Abstract}

Background: Trauma is the first leading cause of death and disability in the active population in developing countries. In Iran, traumatic injuries are the second leading cause of death after cardiovascular disease and also the leading cause of years of life lost (YLL). Population-based surveys can estimate all types of injuries. This study aimed to estimate the annual incidence of nonfatal injuries in adults older than 15 years in Kashan.

Methods: In a cross-sectional population-based study, people older than 15 years who were living in Kashan during 2018-2019 were studied. A cluster stratified sampling method was used. Data analysis was performed using SPSS 22 software. Chi-square and t tests and ANOVA were used to analyze the data. Significance level was set as $\mathrm{P} \leq .05$ and confidence interval (CI) at $95 \%$.

Results: In this study, which included 3880 households residing in Kashan during 2018-2019, the incidence of all injuries was estimated to be 70.61(62.60-78.70) per 1000 people in 1 year. For traffic accidents, the incidence was estimated at 36.08 (30.20-42.00) per 1000 in 1 year. Also, 231 (77.7\%) of people with trauma were male, $137(50.0 \%)$ aged 20 to 39 years, and 191 (69.7) were married. The most common cause of injuries $(\mathrm{n}=140 ; 51.1 \%)$ was related to traffic accidents, and among the traffic accidents, the highest cause was motorcycle accident $(\mathrm{n}=99 ; 70.71 \%)$.

Conclusion: The results of this study showed that the highest rate of injuries occurred among men, younger ages, married, and those with primary education. Also, the results showed the most common causes of trauma were injured hand and foot and head, and the most common location in which trauma occurred was street. The findings of this study are important to better explain the epidemiology aspects of injuries in Kashan.

Keywords: Epidemiology, Incidence, Population-based, Trauma

Conflicts of Interest: None declared

Funding: Kashan University of Medical Sciences

\section{*This work has been published under CC BY-NC-SA 1.0 license.}

Copyright $($ Iran University of Medical Sciences

Cite this article as: Sehat Z, Fakharian E, Sehat M, Omidi A. Epidemiology pattern of traumatic injuries of adults older than 15 years in Kashan, Iran: A population-based study in 2018-2019. Med J Islam Repub Iran. 2021 (15 May);35:62. https://doi.org/10.47176/mjiri.35.62

\section{Introduction}

Trauma is one of the most important public health problems worldwide, and it has a considerable portion of burden of disease, especially in young adults. Also, it is the first leading cause of death and disability in the active popula-

Corresponding author: Zahra Sehat, sehat.zahra426@gmail.com

1. Trauma Research Center, Kashan University of Medical Sciences, Kashan, Iran

2. Department of Neurosurgery, Trauma Research Center, Kashan University of Medical Sciences, Kashan, Iran

3. Department of Clinical Psychology, Faculty of Medicine, Kashan University of Medical Sciences, Kashan, Iran tion in developing countries $(1,2)$. More than $90 \%$ of injury-related deaths occur in developing countries. The high burden of these types of injuries is evidence that trauma occurs more fre quently in the young population, where they $\uparrow$ What is "already known" in this topic:

Traumatic injury occurs with different distributions in sex, age, education, marital status, occupation, nationality, race, location, and hour and season of trauma. In Iran, traumatic injuries are the second leading cause of death and also the leading cause of years of life lost.

$\rightarrow$ What this article adds:

This study was conducted to provide more accurate and complete data on injuries. We hope that the findings of this study be useful for taking effective preventive measures for trauma. 
are at their maximum reproductive potential and social activity (3-6). Between 1990 and 2010, annually, more than 5.1 million deaths resulted in all kinds of trauma, including road traffic crashes, falls, burns, violence, homicide, suicide, and work injury (7). In 2013, a total of 973 million injured people received health care and 4.8 million people died from injuries (4). Around the world, 1 out of 10 deaths event is related to trauma, accounting for $11 \%$ of disabilityadjusted life years (DALY) $(8,9)$. In Iran, traumatic injuries are the second leading cause of death and also the leading cause of years of life lost (YLL) $(9,10)$.

The associated mortality, morbidity, and epidemiology of various mechanisms of injury have been studied in Iran, and mortality and morbidity data are available at the national level (11). Although this information has mainly been generated through hospital-based statistics and patient records studies, population-based household studies considering injuries of the different cases are uncommon (1113). However, only population-based studies can estimate all types of nonfatal injuries. Comparable population-based studies on the prevalence, incidence, and severity of injuries can be a useful aid for preventive programs in developing countries (14-16).

Kashan is a city located in Isfahan province and is in the central part of the Islamic Republic of Iran. The area of Kashan (which is among the crowded cities of Iran) is about $9647 \mathrm{~km}^{2}$. It has a population of 448063 and includes 132 101 families (17). Kashan's neighbor from north and northwest is Qom, from the east and northeast a desert plain, from the southeast Ardestan, and from south Natanz.

This study aimed to estimate the annual incidence of nonfatal injuries in the population of older than 15 years in Kashan during 2018-2019. This study was conducted to provide more accurate and complete data on injuries.

\section{Methods}

\section{Study Design and Population}

This cross-sectional study was conducted on people over 15 years who were residing in Kashan during 2018-2019. This study had a 2-stage stratified cluster design. In the primary stage stratified sampling, Kashan was divided into 5 regions based on socioeconomic status. In the second stage, clusters $(n=320)$ were defined on the map based on the geographical map of Kashan. According to the population of each area, the sample size was determined in 5 regions. All clusters in each area were numbered, and the clusters were randomly selected. In each cluster, 1 household from the 5 houses on the right was randomly selected and the next 25 houses were systematically checked and 1 person aged 15 years and older were randomly selected for an interview; and first the study consent form was filled out for that person (18).

If the selected person was not present or not cooperative for the first time, the interviewer referred 3 times to complete the information. If the selected person did not cooperate or was absent even then, the first house to the right was replaced.

\section{Sample Size}

According to the annual incidence of all injuries $\mathrm{P}$ was assumed to be about 25 per 1000 person-years in 2013 (19), and the following formula was used to estimate the minimum needed sample size. Considering $\mathrm{d}=1.5$

$$
n=\frac{Z_{1-\alpha / 2}^{2} \times p \times q}{d^{2}}
$$

Due to the incidence of trauma of $32.3 \%$, the required sample size for the study was $n=\frac{963}{32.2 \%}=2981$; then, this number was multiplied by 1.5 in the design effect, and a total of 3875 study samples were determined $(19,20)$.

\section{Data Collection}

Interviewers were divided into 5 groups, with each including 2 people who received the necessary training during the 3 days' workshop. They were provided with a 7 pages' guideline providing a full description of the interviewers for their potential future referrals.

During the data collected by the interviewers, the supervisory team oversaw data collection. Ten percent of the data collected from any interviewers was checked by the supervisor for the safety of data. If more than $10 \%$ of data was inaccurate after a random check, the information completed by that interviewer was deleted, and the competence of that interviewer was reevaluated.

In this study, the interviewers asked about any injury that had occurred during the past year, and injury was defined as any intentional or unintentional physical injury that needs medical service whether received or not and with or without intervention. Also, we categorized injury into minor ( $\leq 30$ days of disability) or major ( $>30$ days of disability), and 2 annual incidences were estimated from each mechanism of injury. Also, in this study disability was defined as any condition that restricts everyday activities.

\section{Data Analysis}

In this study, all data analysis was performed using SPSS 22 and Stata 12 software. The student s t test and ANOVA were used to analyze continuous variables, and the chisquare test was used to analyze categorical variables. Frequency and survey logistic option were used to adjust for design effect and calculation valid estimates. Injury incidences are present as incidence per 1000 population and $95 \%$ confidence interval (CI) was calculated for point estimates of incidences using Poisson or binomial distribution assumptions accordingly. The significance level was considered less than 0.05 .

\section{Results}

In this study, to collect the required samples we referred to 4800 households: of these, 4200 people agreed to be interviewed (response rate $=87.5 \%$ ). A total of 180 of the collected data were incomplete and unusable, and 140 of the collected data were incorrect, which were excluded from the study in the monitoring and evaluation phase of the study. In total, 3880 households were surveyed and their data were analyzed. Of the total people interviewed in the study, 1804 (46.5\%) were male and 2076 (53.5\%) were female. To calculate the annual incidence of injuries, we used data on the 274 (7.06\%) people who reported injuries during the past year, with 161 minor injuries (123 males; 38 


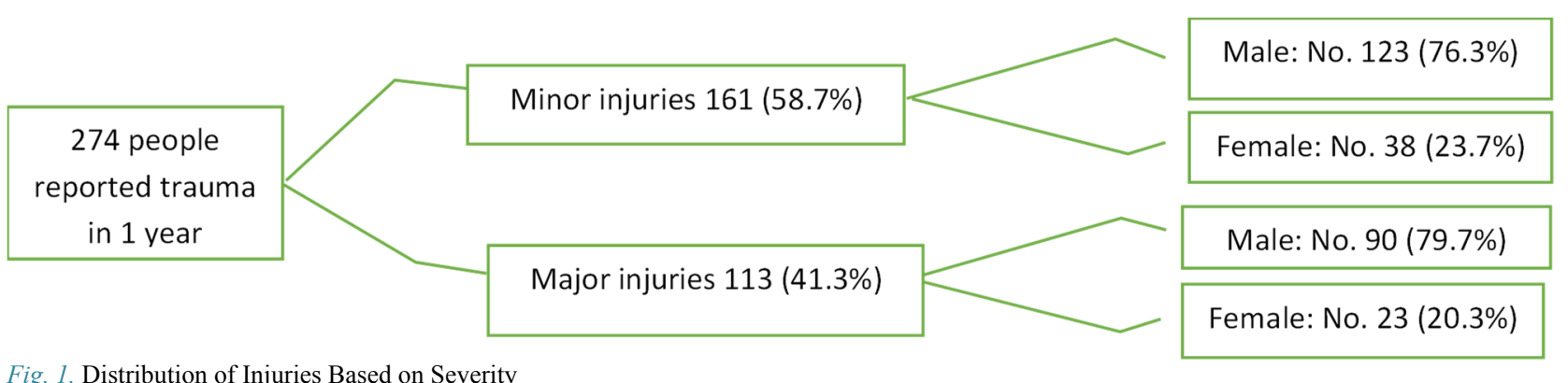

Fig. 1. Distribution of Injuries Based on Severity

females) and 113 major injuries (90 males; 23 females), and data on all injuries were used to provide descriptive details of the mechanisms of injury. Figure 1 shows the distribution of injuries based on severity.

In this study, $274(7.06 \%)$ reported injuries that occurred during the past year, $213(77.73 \%)$ of people with injury were male. In other words, the male-to-female ratio with injury was $3.4(2.13 / 61)$. In this study, $11.8 \%(213 / 1804)$ of the male population reported injury, and $2.93 \%$ $(61 / 2076)$ of the total female population reported injury. People reported trauma mostly aged 21 to 39 years and 137 $(50.0 \%)$ and $7.65 \%(21 / 823)$ of people aged 21 to 29 years and $8.05 \%(74 / 919)$ of people aged 30 to 39 reported injury during the past year.

In this study, $943(24.3 \%)$ of the total people were single and $83(8.7 \%)$ of them experienced trauma; 2937 (75.7\%) were married, and $191(6.5 \%)$ of the married population reported injuries during the past year.

The total injury rate in Persian race in Kashan was 7.02\% (263/3743) during the past year, and in non-Persian race was $8.02 \%$ (11/137). According to the result of this study, the highest rate of injury had occurred in people with primary education $136(49.6 \%)$. Table 1 shows the demographic characteristics of the study population-based trauma injury during the past year.

Mechanism and incidence for injuries in this study are shown in Table 2. About the mechanism of the injuries, the most common cause $(n=140 ; 51 \%)$ was related to traffic accidents, and among the traffic accidents, the highest cause was motorcycle $(\mathrm{n}=99 ; 70.71 \%)$. The second leading cause of injuries was fall $(\mathrm{n}=58)$, with $21.2 \%$ of the causes of the trauma. The number of occupational injuries was $22(8.01 \%)$. Injury severity was also reflected by the number of disability days. In men, based on incidence alone, most major injuries were related to motorcycle accident (63.3\%; (57/90); also, in women, most major injuries were associated with motorcycle accident $(30.4 ; 7 / 23)$ and fall $(30.4 ; 7 / 23)$.

In this study, the incidence of traumatic injuries was estimated to be 70.61(62.60-78.70) per 1000 people. And for traffic accidents, the incidence was estimated at 36.08 (30.20-42.00) per 1000. Figure 2 shows the incidence rate of different incidents per 1000 people in the city of Kashan

Table 1. Demographic Characteristics of the Study Population Based on Trauma Injury During the Past Year a

\begin{tabular}{|c|c|c|c|c|c|}
\hline \multicolumn{2}{|c|}{ Demographic Characteristics } & \multicolumn{3}{|c|}{ Trauma During 2018-2019 ${ }^{a}$} & \multirow[t]{2}{*}{$\mathrm{p}$} \\
\hline & & Male & Female & Total & \\
\hline \multirow[t]{6}{*}{ Age group } & $15-20$ & $16(7.5 \%)$ & $5(8.2 \%)$ & $21(7.7 \%)$ & 0.046 \\
\hline & $21-29$ & $47(22.1 \%)$ & $16(26.2 \%)$ & $63(23 \%)$ & \\
\hline & $30-39$ & $57(26.8 \%)$ & $17(27.9 \%)$ & $74(27 \%)$ & \\
\hline & $40-49$ & $40(18.8 \%)$ & $1(1.6 \%)$ & $41(15 \%)$ & \\
\hline & $50-59$ & $29(13.6 \%)$ & $10(16.4 \%)$ & $39(14.2 \%)$ & \\
\hline & $60 \geq$ & $24(11.2 \%)$ & $12(19.7 \%)$ & $36(13.1 \%)$ & \\
\hline \multirow[t]{2}{*}{ Marital status } & Single & $67(31.5 \%)$ & $16(26.2 \%)$ & $83(30.3 \%)$ & 0.091 \\
\hline & Married & $146(68.5 \%)$ & $45(73.8 \%)$ & $191(69.7 \%)$ & \\
\hline \multirow[t]{4}{*}{ Education } & Illiterate & $7(3.3 \%)$ & $6(9.8 \%)$ & $13(4.7 \%)$ & 0.033 \\
\hline & Primary & $116(54.5 \%)$ & $20(32.8 \%)$ & $136(49.6 \%)$ & \\
\hline & Diploma & $46(21.6 \%)$ & $16(26.3 \%)$ & $62(22.6 \%)$ & \\
\hline & Academic & $44(20.6 \%)$ & $19(31.1 \%)$ & $63(23.4 \%)$ & \\
\hline \multirow[t]{6}{*}{ Occupation } & Unemployed & $5(2.4 \%)$ & 0 & $5(1.8 \%)$ & 0.001 \\
\hline & Household & 0 & $45(73.8 \%)$ & $50(18.2 \%)$ & \\
\hline & Government employee & $92(43.1 \%)$ & $8(13.1 \%)$ & $82(36.5 \%)$ & \\
\hline & Non- government employee & $75(36.05 \%)$ & $1(1.6 \%)$ & $76(27.7 \%)$ & \\
\hline & Retired & $20(9.6 \%)$ & 0 & $20(7.3 \%)$ & \\
\hline & Student & $16(7.6 \%)$ & $7(11.5 \%)$ & $23(8.5 \%)$ & \\
\hline \multirow[t]{7}{*}{ Nationality and race } & Fars & $182(85.4 \%)$ & $54(88.5 \%)$ & $236(86.1 \%)$ & 0.004 \\
\hline & Turk & $13(6.1 \%)$ & 0 & $13(4.7 \%)$ & \\
\hline & Kurd & $2(0.9 \%)$ & $2(3.3 \%)$ & $4(1.5 \%)$ & \\
\hline & Lure & $7(3.3 \%)$ & 0 & $7(2.6 \%)$ & \\
\hline & Gilak & $2(0.9 \%)$ & 0 & $2(0.7 \%)$ & \\
\hline & Arab & 0 & $1(1.6 \%)$ & $1(0.4 \%)$ & \\
\hline & Non Persian & $7(3.3 \%)$ & $4(6.6 \%)$ & $11(4.0 \%)$ & \\
\hline Total & & $213(100 \%)$ & $61(100 \%)$ & $274(100 \%)$ & \\
\hline
\end{tabular}




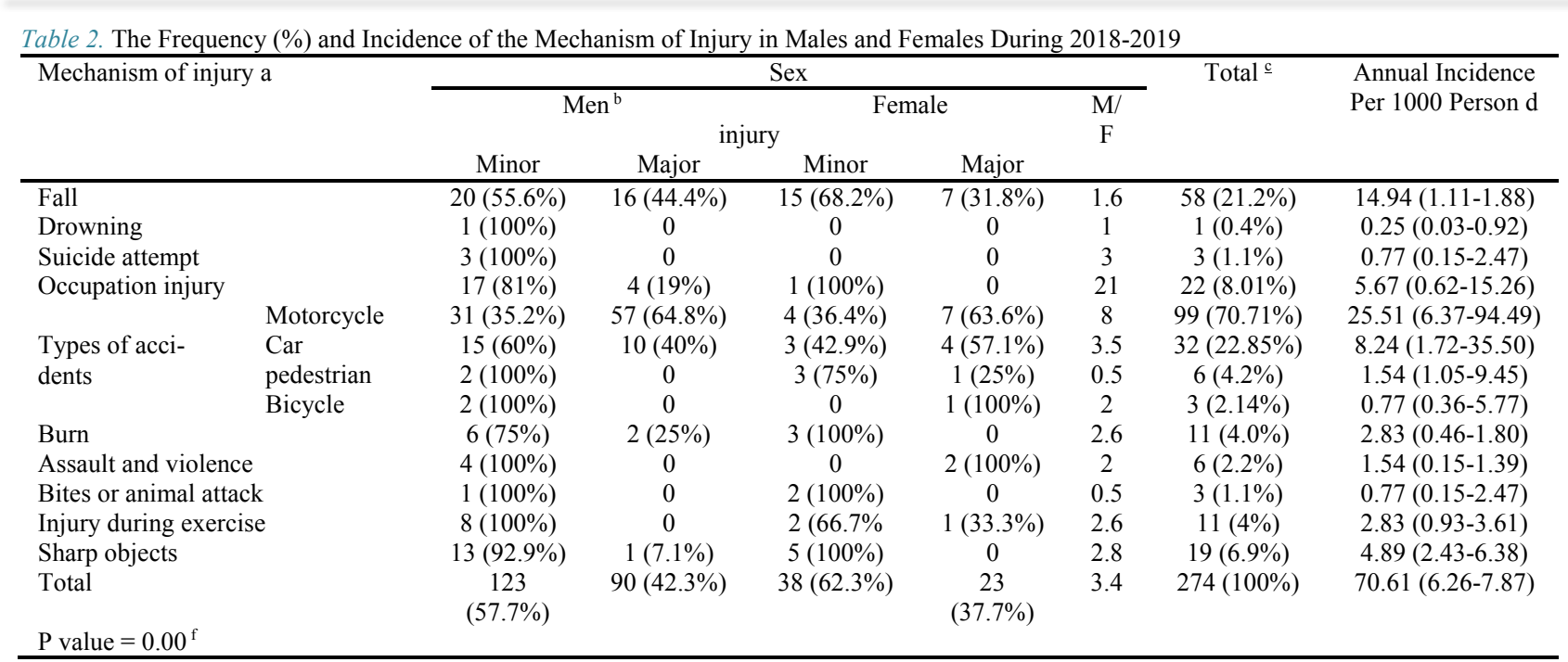

$\frac{\mathrm{P} \text { value }=0.00}{\mathrm{a} \text { Injury that needed any medical care. }}$

${ }^{b}$ Data are presented as $\mathrm{n}(\%)$.

c Percent of total injuries.

d Incidence per 1000 person-year $(95 \% \mathrm{CI})$.

${ }^{\mathrm{f}}$ Student's $\mathrm{t}$ test.

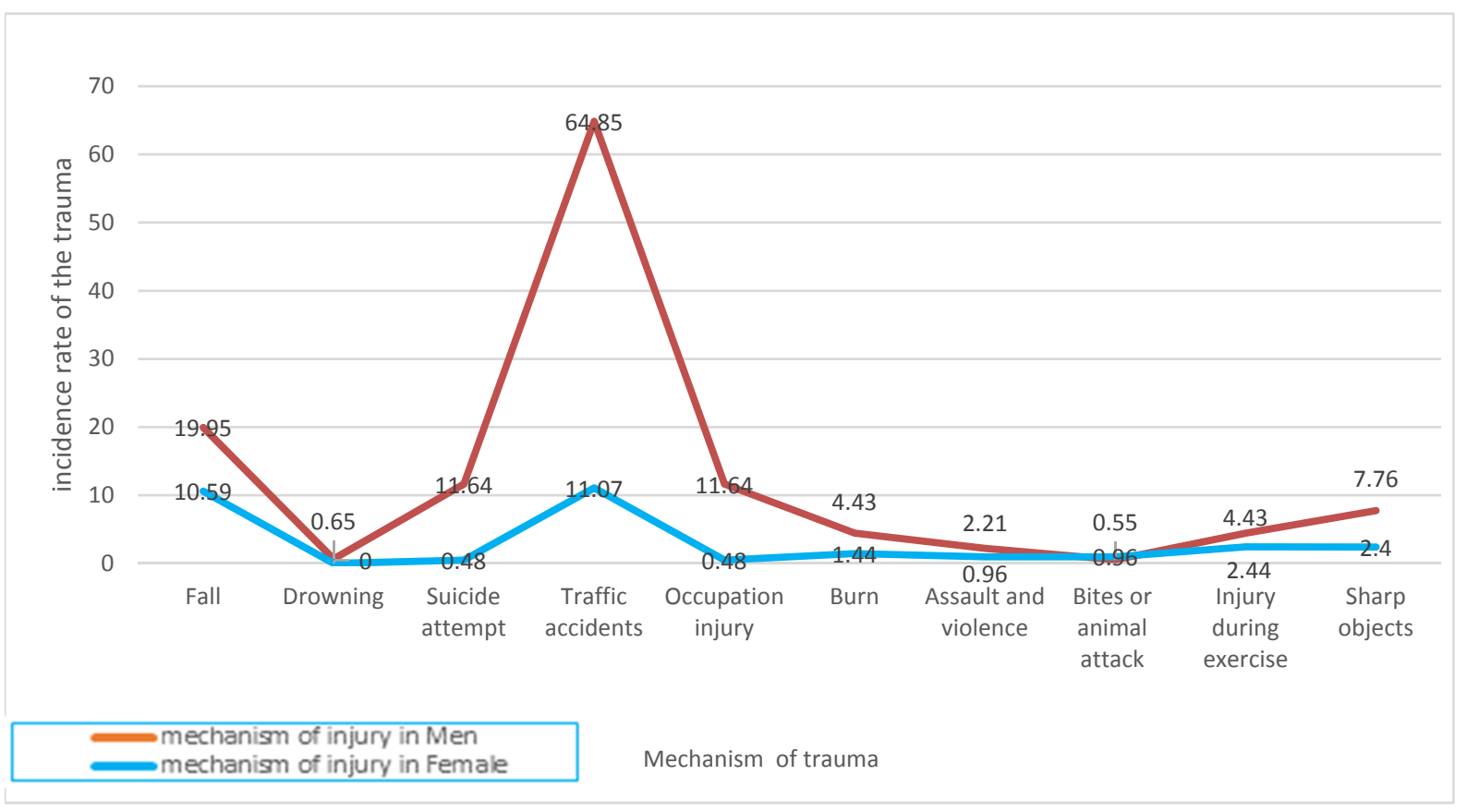

Fig. 2. The Incidence Rate of Trauma in Males and Females per 1000 People Annually

in 1 year.

In 1 day, the lowest incidence of trauma $(n=8 ; 2.9 \%)$ occurred between $1 \mathrm{AM}$ to $6 \mathrm{AM}$, and between $7 \mathrm{AM}$ to 12 noon, and $91(33.3 \%)$ of the total trauma occurred between 1 PM to18 PM, and $92(33.6 \%)$ between hours 7 PM to 12 midnight $(\mathrm{n}=83 ; 30.3 \%)$. Most of the place that trauma occurred was street $127(46.35 \%)$ and then in second place at home 51(18.61\%) and work (14.96) and then elsewhere. The highest incidence of trauma occurred in May $(\mathrm{n}=$ $38 ; 13.9 \%)$ and April $(\mathrm{n}=37 ; 13.5 \%)$. Figure 3 shows the distribution of the time, location, and season of trauma.
Among trauma patients, the most injuries were in the upper and lower limbs (hand: 74; 17.28\%; foot: 88; 20.56\%). The rate of head and skull injury was $45(10.51 \%)$ and abdominal injuries accounted for $22(5.14 \%)$ of the total injuries. Figure 4 shows the distribution of injury according to the body organs.

In the total number of injuries that occurred in body organs, $153(46.7 \%)$ were fractures, $66(19.87 \%)$ ruptures, 9 $(2.75 \%)$ burn injuries, and $14(4.28 \%)$ head injuries. Table 3 shows the distribution of various injuries.

Of those with trauma in this study, 189 (68.9\%) had multiple injuries. Among the various mechanisms of trauma, 

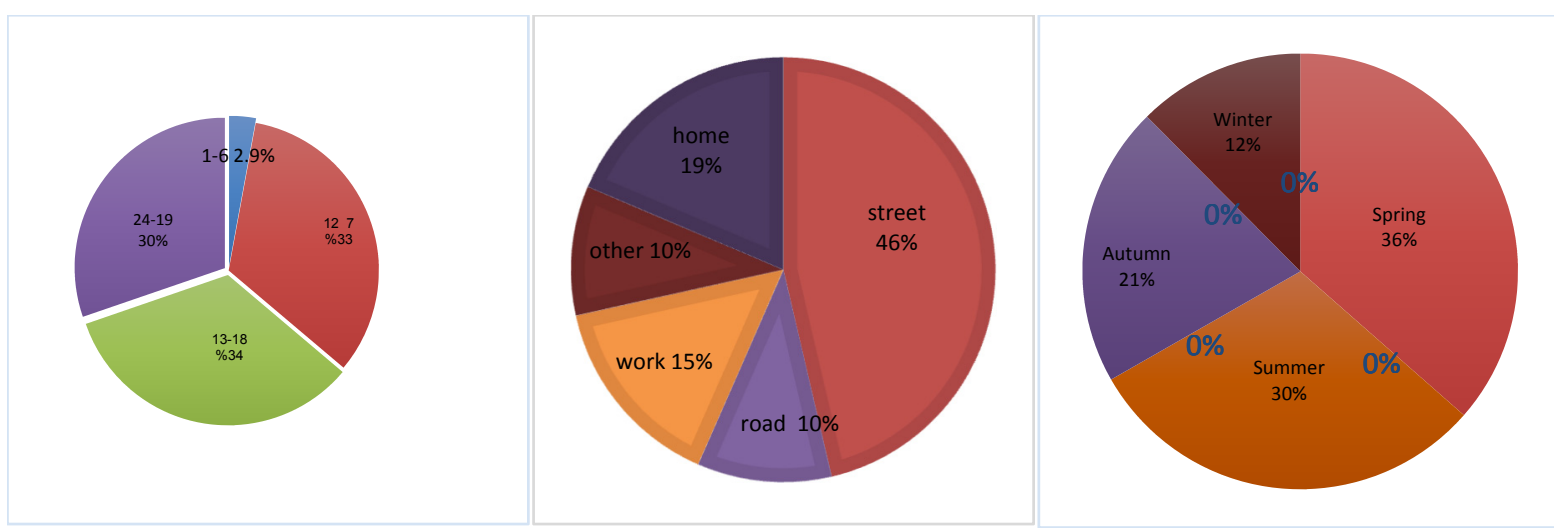

Fig. 3. Time, Place, and Season of Traumatic Injuries

${ }^{a}$ The value is the percentage of each category

motorcycle accidents had the highest number of multitraumatic events $(87 \% ; 77 / 99)$ and mechanisms such as falls $(37.2 \% ; 22 / 58)$, work trauma $(63.3 \% ; 14 / 22)$, and sharp objects $(14 ; 73 \%)$ resulted in single trauma. Figure 5 shows the number of injuries due to the mechanism of injury.

In this study, of people with trauma during the past year, $89(32.48 \%)$ had less than 24 hours' hospital stay, and 185 (67\%) had more than 24 hours' hospitalization due to trauma. Among hospitalized patients, 114 (41.40\%) received surgical treatment and $160(58.39 \%)$ received nonsurgical treatment. Also, 48 (17.5\%) of people with trauma in this study reported a history of severe trauma in their lifetime.

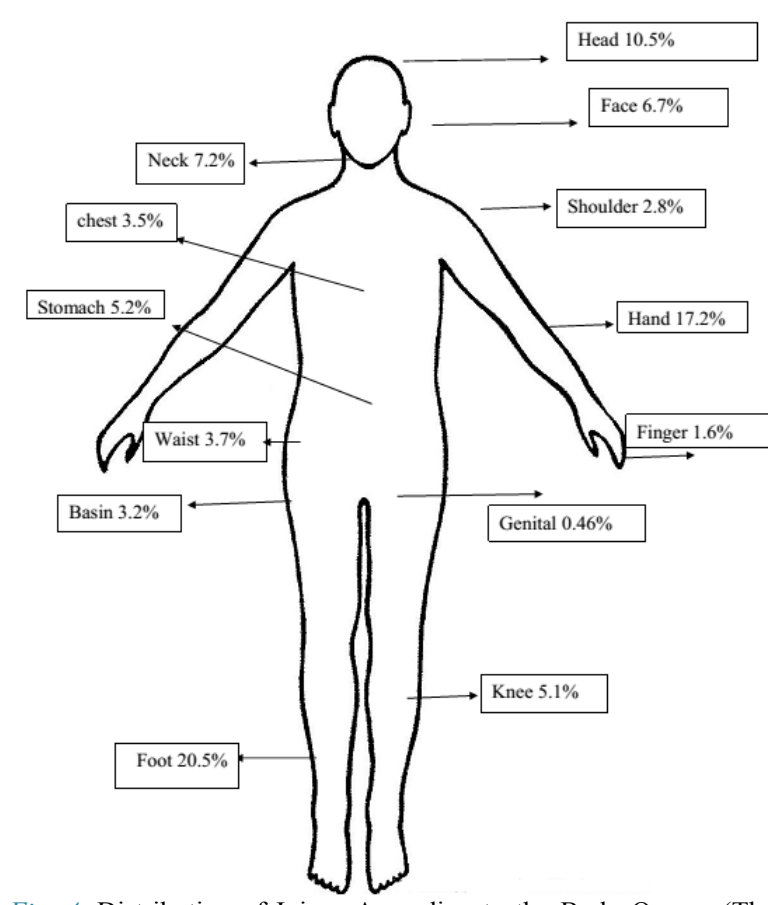

Fig. 4. Distribution of Injury According to the Body Organs (The values represent the percentage of all trauma.)

\section{Discussion}

This study aimed to estimate the annual incidence of injuries in the urban population of Kashan with a population of 448063 . We referred to the households residing in Kashan during 2018-2019 and asked them about all their injuries during the past year. The injury incidence rate in the urban community under study was 70.6 in 1000 people annually.

To avoid the underestimation of injury incidence, we used a household survey. Hospital-based data could be misleading when they are used to estimate nonfatal injuries because all those with injuries have not been admitted to hospitals. Also, admission to hospitals is influenced by several factors such as severity of injury, health system structure, and access to services (19).

In this study, most people with injuries were males aged 20 to 39 years. The male to female ratio was 3.4. The rate of trauma among men was $11.8 \%$, and in women was $2.93 \%$, respectively. This finding is consistent with that of previous studies (20-22). In developing countries, the male to female ratio is significantly high, which can be attributed to social status, the differences in attitudes, daily activities, cultural factors, behavioral/physical differences, differences in exposure to road traffic, and a higher rate of men's travels than women. It can also be attributed to high-risk behaviors of men when driving and passing through streets, and women's jobs, and fewer activities outside home (most women are housewives). Also, $75.7 \%$ of people with trauma were married. The highest rate of trauma (35\%) occurred in people with primary education; this finding is consistent with the results of the studies conducted in Iran and other counties in the Middle East $(23,24)$. The results of this study showed that most of the traumatic events, especially traffic accidents, had occurred in March and April, respectively. In February and March of each year Kashan gets very crowded due to the annual rose water event. Also, a large number of travelers visit this city in April and March, and thus the rates of traffic accidents are high during this time. These findings are consistent with a previous study in Iran (25), as this period is a vacation time of the year, and most accidents occurred due to the increasing 


\begin{tabular}{|c|c|c|c|}
\hline Type of Injury & Minor Injury a & Major Injury & Incidence $^{\mathrm{b}}$ \\
\hline Fracture & $67(43.7 \%)$ & $86(56.2 \%)$ & 39.43 \\
\hline Spinal cord injury & 0 & $2(100 \%)$ & 0.51 \\
\hline Bleeding & $1(50 \%)$ & $1(50 \%)$ & 0.51 \\
\hline Ligament rupture & $3(100 \%)$ & 0 & 0.77 \\
\hline Head injury & $6(42.8 \%)$ & $8(57.1 \%)$ & 0.25 \\
\hline Amputation & 0 & $2(100 \%)$ & 0.51 \\
\hline Torsion limb & $5(55.5 \%)$ & $4(44.4 \%)$ & 0.23 \\
\hline Stuffiness by gas & $1(100 \%)$ & 0 & 0.25 \\
\hline Chemical poisoning & $1(100 \%)$ & 0 & 0.25 \\
\hline Hearing loss & 0 & $1(100 \%)$ & 0.25 \\
\hline Speech disorders & $3(100 \%)$ & 0 & 0.77 \\
\hline Drug intoxication & $2(100 \%)$ & 0 & 0.51 \\
\hline Dislocation & $4(20 \%)$ & $16(80 \%)$ & 5.15 \\
\hline Rupture & $57(86.3 \%)$ & $9(13.6 \%)$ & 16.75 \\
\hline Burn & $8(88.8 \%)$ & $1(11.2 \%)$ & 2.31 \\
\hline Total & $161(58.7 \%)$ & $113(41.2 \%)$ & 73.96 \\
\hline
\end{tabular}

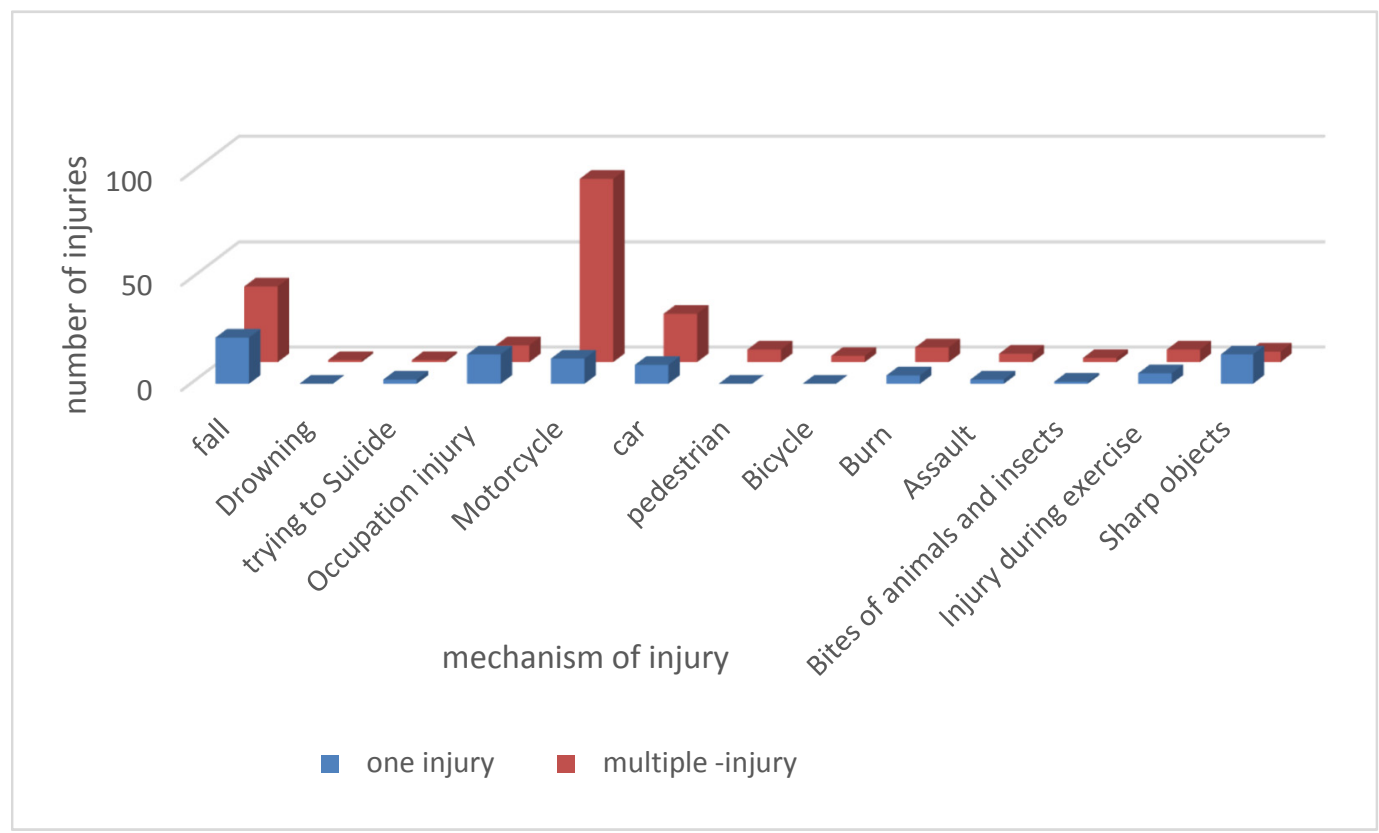

Fig. 5. Number of Injuries due to the Mechanism of Injury

number of journeys and traveling.

The result of this study shows that $51 \%$ of the mechanism of trauma was related to traffic accidents, and among the traffic accidents, the highest cause was motorcycle $(70.71 \%)$. The second leading cause of trauma was fall (21.2\%).

Most injuries were to limbs (hand: 17.28\%; foot: $20.56 \%$ ). The rate of head injury was $10.51 \%$. In this study, $46.7 \%$ reported fracture, $19.87 \%$ reported rupture, and $2.75 \%$ burn injury. Another study confirmed this result in Kashan and other cities of Iran similar to this study in a 2009 study in Kermanshah, which was an epidemiologic study of traumatic injury. The mean age of patients was 34.7 years, and the number of males, unemployed, and illiterate patients predominated over other patients. Traffic accidents' crashes and personal conflicts were the most common injury mechanisms. Among these, the highest proportion were those affected by traffic accidents and pedestrians (19.22-24).
Also, a cross-sectional study has been done in Kashan for investigating the epidemiology of trauma in Shahid Beheshti hospital during 2007-2008. In this study, about 1004 patients were examined, most trauma patients were in the age group of 21-30 years, most of the damage was caused by motorcycle followed by car accidents, and the majority of those affected were those with primary education (25).

A study in Tehran interviewed 22128 households to determine the prevalence of traffic accidents in Tehran. The results showed that the incidence of traffic accidents was $17.3 \%$ out of every 1000 people per year. In this study, traffic accidents were more frequent in men than in women. This value was higher in men for motorcycle and bicycle accidents and higher in pedestrians for women. This concerns the gender role of men and women and that women have social restrictions on driving motorcycles and bicycles. Marital status and ethnicity had no significant effect on the risk of trauma in Tehran; it was also found that traffic 
accidents are more common in younger age groups, motorists, and pedestrians $(26,27)$. In another study in Pakistan (which is a developing country and like Iran is located in southeast Asia), in which sampling was done based on demographic data and during the stratification of the society based on economic and social levels, It was concluded that the annual incidence of unintentional trauma is 45.9 per 1000 people over the age of 5 , or about 6.16 million unintentional trauma occur in Pakistan annually due to falls, animal bites, and burns. In this study, the most common site of damage was street and then roads (28).

Traffic accidents are one of the major public health problems in a developing country, and its continuous and effective prevention requires coordinated and comprehensive efforts. Kashan is one of the cities in Iran with a high mortality rate, comprehensive studies on epidemiology and factors affecting the outcomes of traffic accidents can be considered an important step towards controlling the risk factors and reducing the burden of these incidents in the country.

\section{Study Limitations}

This population-based study had many limitations in any 1 stage. While the data were randomly collected, it might not be a complete indicator of the community. However, the data did not completely match the age and sex structure estimates for Kashan.

In this type of study, households were reluctant to report certain injuries with social implications or feared consequences of reporting events such as self-poisonings or suicidal behaviors and injuries of family violence.

A significant reminder bias that leads to a reduction in disability is reported over time, as people are more likely to remember minor injuries in the past. And people who have been injured in recent months have reported fewer posttraumatic stress disorders than in previous months.

\section{Conclusion}

The results of this study showed that the highest incidence of trauma was among men, younger age, married, and those with primary education. Also, the result showed that the most common causes of trauma were injured hand and foot and head, and the most location that trauma occurred was street. According to this study, the real incidence of nonfatal injuries is more than the formal estimates that are hospital-based.

It is recommended that some health policies be improved to prevent trauma. Also, young people should be educated about the dangers of the traffic accident, especially injury caused by motorcycle accidents.

\section{Acknowledgments}

This study was derived from a PhD dissertation and supported by a grant from Kashan University of Medical Sciences' Foundation. Also, this study received a research project code and code of ethics.

\section{Conflict of Interests}

The authors declare that they have no competing interests.

\section{References}

1. Khaji A, Ghodsi M, Eftekhar B, Karbakhsh M. Trauma Research in Iran: A Report of the Sina Trauma Data Bank. Arch Iran Med. 2010;1(13):17-20.

2. Alexandrescu R, O'Brien SJ, Lecky FE. A review of injury epidemiology in the UK and Europe: Some methodological considerations in constructing rates. BMC Public Health. 2009;9:226.

3. Pouraghaei M, Sadeghpour A, Moharamzadeh P, Ala A, Bagheri Asl M M. Epidemiological study of trauma patients referred from Imam Reza trauma center to Shohada orthopedic center in Tabriz, Iran, during 2015. J Anal Res Clin Med. 201 7;5(2):33-7.

4. Haagsma JA, Graetz N, Bolliger I, Naghavi M, Higashi H, Mullany EC, et al. The global burden of injury: incidence, mortality, disabilityadjusted life years and time trends from the Global Burden of Disease study 2013. Inj Prev. 2016;22(1):3-18.

5. Montazeri A. Road-traffic-related mortality in Iran: a descriptive study. Public Health. 2004;118:110-13.

6. Hemmati H, Kazemnezhad-Leili E, Mohtasham-Amiri Z, Darzi AA, Davoudi-Kiakalayeh A, Dehnadi-Moghaddam A, et al. Evaluation of chest and abdominal injuries in trauma patients hospitalized in the surgery ward of poursina teaching hospital, guilan, iran. Arch Trauma Res. 2013 Winter;1(4):161-5.

7. Lafta R, Al-Shatari S, Cherewick M, Galway L, Mock C, Hagopian A, et al. Injuries, Death and Disability Associated with 11 Years of Conflict in Baghdad, Iraq: A Randomized Household Cluster Survey. PLoS One. 2015;10(8):e0131834.

8. Murray CJ, Vos T, Lozano R, Naghavi M, Flaxman AD, Michaud C, et al. Disability-adjusted life years (DALYs) for 291 diseases and injuries in 21 regions, 1990-2010: a systematic analysis for the Global Burden of Disease Study 2010. Lancet. 2012;380(9859):2197-223.

9. Yadollahi M, Mokhtari AM, Malekhoseini HR. Fatality Rate of Trauma Victims in Southern Iran: A Five-Year Survey. Trauma Mon. 2018 January;23(1):e42081.

10. Akbari ME, Naghavi M, Soori H. Epidemiology of deaths from injuries in the Islamic Republic of Iran. East Mediterr Health J. 2006;12:382-90.

11. Rahimi-Movaghar V, Zarei MR, Saadat S, Rasouli MR, Nouri M. Road traffic crashes in Iran from 1997 to 2007. Int J Inj Contr Saf Promot. 2009;16:179-81.

12. Hafezi-Nejad N, Rahimi-Movaghar A, Motevalian A, Amin-Esmaeili, Sharif V, Hajebi A, et al. A nationwide population-based study on incidence and cost of non-fatal injuries in Iran. Inj Prev. 2014;0:1-5.

13. Emamian MH, Zeraati H, Majdzadeh R, Shariati M, Hashemi H, Fotouhi A. The Gap of Visual Impairment Between Economic Groups in Shahroud, Iran: A Blinder-Oaxaca Decomposition. Am J Epidemiol. 2011;173(12):1463-7.

14. Lehtola S, Koistinen P, Luukinen H. Falls and injurious falls late in home-dwelling life. Arch Gerontol Geriatr. 2006 Mar-Apr; 42(2):21724.

15. Aghakhani K, Ameri E, Ameri M, Mohtarami SA. Epidemiology of orthopedic trauma in children and adolescent in a referral center in Tehran: a prospective study. Tehran Univ Med J. 2015;73(1):40-8.

16. Reihani H, Pirazghandi H, Bolvardi E, Ebrahimi M, Pishbin E, Ahmadi K, et al. Assessment of mechanism, type and severity of injury in multiple trauma patients: A cross sectional study of a trauma center in Iran. Chin J Traumatol. 2017;20:75-80.

17. Fakharian E, Sehat Z, Sehat M. Traumatic spine injury in Kashan, Iran. J Emerg Pract Trauma. 2019;5(2):65-70.

18. Khosrozadeh H, Alavi NM, Gilasi H, Izadi M. Oral health-related quality of life in older people in Kashan/Iran 2015. Nurs Midwif Stud. 2017;6:182-8.

19. Saadat S, Mafi M, Sharif-Alhoseini M. Population based estimates of non-fatal injuries in the capital of Iran. BMC Public Health. 2011;11(608).

20. Vles WJ, Steyerberg EW, Essink-Bot ML,van Beeck EF, Leenen LP. Prevalence and determinants of disabilities and return to work after major trauma. J Trauma. 2005;58(1):126-35.

21. Rakhshani T, Kashfi SM, Idani F, Ebrahimi MR, Hashemi Nazari SS. An Epidemiology Study of Deaths from Road Traffic Accidents, Iran, Ahvaz. J Health Sci Surveillance Sys. 2018;6(1):46-51.

22. Izadi N, Najaf Farid F, Khosravi A, Hashemi Nazari S, Salari A, Soori H. Estimation of mortality and calculated years of lost life from road traffi injuries. J Mazandaran Univ Med Sci. 2014;24(112):51-8.

23. Izadi N, Soori H, Najaf F, Hashemi nazari SS, Khosravi A, Salari A. 
Epidemiological Pattern of Road Traffic Injuries in Kermanshah District in 2010. Hakim Health Sys Res. 2014;17(3):177- 83.

24. Karbakhsh M, Zandi NS, Rouzrokh M, Zarei MR. Injury epidemiology in Kermanshah: The National Trauma Project in Islamic Republic of Iran. East Mediterr Health J. 2009 Jan-Feb;15(1):57-64.

25. Davoodabadi A, Yazdani A. Sayyah M, Mirzadeh Javaheri M.Trauma epidemiology and its consequences in victims referred to Kashan Trauma Center during 2007-8. Feyz J Kashan Univ Med Sci. 2011;14(5):500-5.

26. Sehat M, Holakouie Naieni K, Asadi-Lari M, Rahimi Foroushani A, Malek- Afzali H. Socioeconomic Status and Incidence of Traffic Accidents in Metropolitan Tehran : A Population-based Study. Int J Prev Med. 2012 Mar;3(3):181-90.

27. Motevalian A, Safari R, Asadi-Lari M. Socioeconomic Inequality in road traffic injuries in Tehran. Injur Prev J. 2012 October 1;18(Suppl 1):A212.

28. Fatmi Z, Hadden WC, Razzak JA, Qureshi HI, Hyder AA, Pappas G. Incidence, patterns and severity of reported unintentional injuries in Pakistan for persons five years and older: Results of the National Health Survey of Pakistan 1990-94. BMC Public Health. 2007;7(152). 